\title{
Las expectativas de búsqueda del primer empleo de universitarios con formación híbrida. El caso de una universidad pública mexicana ${ }^{1}$
}

\section{Expectations of first job search of college graduates with hybrid training. The case of a mexican state university}

\author{
ISSN 1510-2432 - ISSN 1688-9304 (en línea) - DOI: http://dx.doi.org/10.18861/cied.2015.6.2.35
}

Javier Simón

Doctor (Cand.) en Enseñanza Superior, Centro de Investigación y Docencia en Humanidades del Estado de Morelos, México. Master en Administración, Universidad Autónoma de Guerrero, México. Master en Ciencias de la Educación, Instituto de Estudios Universitarios A.C., México. Licenciado en Contaduría, Instituto Tecnológico de Acapulco, México. Profesor investigador adscrito al Departamento de Ciencias Empresariales, Universidad del Papaloapan, Oaxaca, México.

Fecha de recibido: 11/03/2015

Fecha de aceptado: 17/04/2015

\section{Resumen}

Se presentan algunos resultados de una investigación cualitativa más amplia cuyo objetivo principal es identificar los factores que facilitarían u obstaculizarían la inserción laboral de los egresados universitarios con formación híbrida.

A partir de las representaciones sociales de diez egresados de la Licenciatura en Ciencias Empresariales fue posible identificar tres factores que facilitarían la consecución del primer empleo tales como la formación multidisciplinaria, la calidad de su formación universitaria y el prestigio de su universidad de origen. En escasa medida algunos refieren desde su propio imaginario tres factores obstaculizadores en su inserción laboral: la falta de liderazgo y sociabilidad, la falta de experiencia laboral y el bajo promedio escolar obtenido a lo extenso de su formación universitaria.

Palabras clave: Inserción laboral, mercado de trabajo, egresado universitario, educación híbrida.

\begin{abstract}
The present article shows some results extracted from a broader qualitative research whose main objective is to identify factors that facilitate or hinder the job placement of university graduates with hybrid training. From social representations of ten graduates with Bachelor degrees in Business Sciences (Licenciatura en Ciencias Empresariales) it has been possible to identify three factors that facilitate the achievement of their first job, such as mutidisciplinary-training, the quality of university education, and the prestige of the university. From their personal viewpoints, and to a lesser extent, graduates refer to three hindering factors in their employment; the lack of leadership and social skills, the lack of work experience, and low school grades obtained throughout their university education.
\end{abstract}

Key words: Job placement, job market, college graduates, hybrid education. 


\section{Introducción}

Actualmente se afirma que los empleadores requieren que los egresados universitarios posean una formación polivalente y flexible para adquirir y utilizar conocimientos, capacidades y habilidades comunes a varias áreas con versatilidad suficiente para la adaptación y la transición ocupacional (De Ibarrola, 2007).

En México, varios subsistemas de educación superior están creando carreras profesionales que articulan dos o más disciplinas tradicionales dando origen a las carreras universitarias híbridas (Dgest, 2009; CUP, 2009; Barrón y Gómez, 2004). Los institutos tecnológicos a partir del año 2009 ofertan la Ingeniería en Gestión Empresarial y las universidades tecnológicas la Ingeniería en Desarrollo e Innovación Empresarial y la Ingeniería en Administración. No obstante, dichos programas educativos constituyen una instrucción unilateral emanada desde los órganos rectores nacionales (Dirección General de Institutos Tecnológicos y Coordinación General de Universidades Tecnológicas), pues no se han presentado de manera pública las evidencias de las necesidades reales de profesionales de este tipo por parte de las empresas. Se afirma que las carreras profesionales híbridas permiten a los graduados incorporarse con mayores ventajas y facilidades al mercado laboral pues responden a los nuevos esquemas de trabajo caracterizados por la polivalencia, la multidisciplinariedad y la interdisciplinariedad. No obstante, los escasos estudios efectuados sobre el tema han identificado problemas para la inserción laboral (Jiménez, 2009; Damián, 2014). Por lo anterior, surgió el interés por investigar los factores que facilitan y obstaculizan la inserción laboral del Licenciado en Ciencias Empresariales egresado de la Universidad del Papaloapan (UNPA), que ha recibido una formación híbrida.

La Licenciatura en Ciencias Empresariales (en adelante, LCE) se inició en el año 2005, y a la fecha ha recibido a diez generaciones de las cuales ya egresaron cinco (2005-2010, 2006-2011, 2007-2012, 2008-2013 y 2009-2014). Al término del sexto y octavo semestre de su formación universitaria, los alumnos efectúan dos estancias profesionales (prácticas en empresas), con el objeto de acercarlos a la práctica laboral (leepo, 2005). Durante estas prácticas los alumnos expresan que los empleadores desconocen la carrera y el perfil profesional, y los egresados comentan que en su búsqueda de empleo muchos empleadores confunden a la LCE con la Licenciatura en Administración de Empresas (en adelante, LAE). Por tanto, deben explicar al empleador en qué consiste su formación universitaria, situación que desde su óptica los pone en desventaja con otros aspirantes al puesto. Lo anterior hace suponer que los egresados de LCE enfrentan un mercado laboral discriminatorio, lo que hace surgir la siguiente pregunta de investigación: ¿Qué factores facilitan u obstaculizan la inserción laboral de los egresados de carreras universitarias híbridas en un contexto de mercado laboral local?

El objetivo general de la investigación es estudiar y describir el proceso de inserción laboral del Licenciado en Ciencias Empresariales para identificar los factores que facilitan o dificultan dicho proceso tomando en cuenta su perfil profesional híbrido.

Son tres las justificaciones principales de la investigación: 1) abordar un fenómeno escasamente estudiado en México para generar información para esta línea de investigación emergente; 2 ) demostrar que bajo ciertas condiciones las ventajas atribuidas a la formación universitaria híbrida son puestas en tela de juicio, y que no se pueden generalizar para todo el territorio nacional, y; 3) la investigación es una oportunidad para dar voz a los egresados híbridos para que compartan la situación que viven en el proceso de inserción laboral y, a partir de la misma poder evaluar las aseveraciones de la educación universitaria híbrida. 


\section{Marco teórico}

\section{Antecedentes de las profesiones universitarias híbridas}

La necesidad de reestructurar la oferta de educación superior obedece a tres factores: 1) mayor flexibilidad, adaptabilidad y pertinencia en la formación profesional para responder a un mercado de trabajo cambiante y dinámico; 2) la imprevisibilidad, la indeterminación, la adaptabilidad, la capacidad de aprendizaje y formación continua como los nuevos términos del mundo del trabajo (Celis y Gómez, 2005), y; 3) las nuevas formas de organización, diferenciación, identidad y apropiación del conocimiento.

Por lo anterior, muchas profesiones caracterizadas por claras definiciones, delimitaciones e identidades de su área o campo del saber están siendo sometidas a importantes presiones y cuestionamientos derivados de la emergencia de nuevos campos híbridos o transdisciplinarios que subsumen y recontextualizan los saberes disciplinarios tradicionales ofreciendo nuevas composiciones, demarcaciones, límites e identidades.

En México se está impulsando una nueva oferta educativa que abandona la práctica de parcializar la realidad y estudiarla de esta manera. Hoy -se afirma- se requiere una mejor interconectividad en las ciencias operando de manera conjunta. Esta exigencia de multidisciplinariedad es lo que ha impulsado la oferta de profesiones híbridas (Universia, 2010). Así, la Secretaría de Educación Pública (SEP) a través de la Subsecretaría de Educación Superior (SES) está orientando, abriendo y ofertando este tipo de carreras en las universidades autónomas estatales, universidades tecnológicas, universidades politécnicas y los institutos tecnológicos (Dgest, 2009; CUP, 2009; Damián, 2014). La Secretaría del Trabajo y Previsión Social (STPS) alude a la necesidad de creación de especialidades transversales y a la polifuncionalidad (STPS, 2010; Universia, 2010), por lo cual las carreras universitarias híbridas representan una estrategia de los sistemas educativos actuales para responder a las exigencias de la organización flexible del trabajo.

\section{Las profesiones universitarias híbridas: finalidades y características}

Según Jiménez (2009), una profesión híbrida se caracteriza por que su "plan de estudios se diseñó a partir de la convergencia de dos disciplinas reconocidas", por lo que cada una de las disciplinas que se mezclan para la hibridación posee una delimitación de su campo de actuación. También utiliza el término profesión interdisciplinaria para explicitar que es una profesión en la que los "conceptos y métodos de dos disciplinas se articulan y subsumen en un objeto común y en una problemática determinada" (p.59). Se atribuyen varias ventajas a las profesiones híbridas, así como para los individuos que opten por este tipo de formación. Holguín (2011) menciona que al romper el paradigma de la especialización este tipo de formación proporciona una oportunidad doble al egresado pues éste puede emplearse en el mercado de trabajo o autoemplearse y que, en caso de emplearse en una empresa sus oportunidades de trabajo se duplican pues por su formación híbrida puede desempeñarse en más de un área, lo que le da acceso a varias opciones laborales. Sin embargo, Páez (2011) afirma que los profesionales híbridos se encuentran en una zona de ambigüedad profesional moviéndose entre las fronteras de las disciplinas que articulan sin una delimitación de su actuación profesional. En concordancia con lo anterior Sáez (2007) puntualiza lo siguiente:

- El campo de actuación del profesionista híbrido es más difícil que el del especialista porque la hibridación es una categoría indefinida. A diferencia del profesional especialista el híbrido en sus inicios no sabe qué conocimientos o trabajos cubre ni con qué intensidad. 
- El profesional especialista elige un campo de conocimientos y de trabajo específico adaptándose y limitándose a la complejidad técnica del campo, mientras que el profesional híbrido tiene una misión más amplia al no limitarse a dominar un campo especializado sino que su participación es de gran utilidad en la solución de problemas importantes que requieren de enfoques complejos y multidisciplinarios.

- La formación híbrida no es dejar de ser especialista en algo pero se tiene que ser menos especialista que los muchos especialistas, aunque lo suficiente como para tener un diálogo fluido y operativo con los especialistas.

En resumen, una profesión universitaria híbrida carece de reconocimiento social e identidad profesional, hecho que se concretiza en el desconcierto y la incertidumbre profesionales respecto de los roles y las funciones a cumplir tanto de los egresados universitarios como de los empleadores (Jiménez, 2009; Páez, 2011).

\section{La conceptualización del término inserción laboral}

Resulta importante definir el concepto de inserción laboral, pues es un referente obligado para esta investigación. Así Barrón et al. (2003:76) la definen “como la consecución y desempeño de un empleo dentro de un área y sector acorde con la formación recibida". De Miguel (1998:23) dice que es "el proceso que recorren los graduados desde que finalizan sus estudios hasta que obtienen un trabajo estable", y García y Gutiérrez (1996:274) mencionan que es el "proceso de incorporación a la actividad económica de los individuos o el conjunto de acciones del denominado job search". Para estos investigadores el proceso se lleva a cabo en la etapa juvenil representando una transición social que va desde una posición que el individuo tiene en el sistema educativo y en la familia de origen, hacia posiciones del mercado de trabajo y de independencia familiar. Por último Vernières (1997:11) lo define como el "proceso por el cual los individuos inactivos acceden a una posición estable en el sistema de empleo", por lo que esta definición apunta a un determinado proceso que inicia por un tipo especial de inactividad (los estudios universitarios) pasando a la acción de buscar un lugar en el mercado de trabajo que posibilite hacer realidad las expectativas laborales creadas durante el proceso formativo.

El proceso de inserción laboral, entonces, se inicia en el momento en que el individuo finaliza su formación universitaria y se plantea salir en la búsqueda de un lugar en el mercado de trabajo. El final del proceso está marcado por la ocupación de un empleo acorde a la formación universitaria recibida y con un status estable. Así, los dos eventos principales que marcan el punto de partida de la inserción laboral son la salida de la universidad y el deseo manifiesto del egresado de ingresar a la vida laboral.

\section{Los modelos para interpretar el proceso de inserción laboral}

Se han generado diversos modelos para analizar el proceso de inserción laboral. Puesto que en este trabajo se trata de recuperar las voces de los egresados, los dos grupos de modelos que se desarrollan a continuación son desde la perspectiva del que busca un empleo (tabla 1). 


\section{Tabla 1. Modelos explicativos del proceso de inserción laboral}

\begin{tabular}{|c|c|}
\hline Grupos & Modelos y supuestos \\
\hline \multirow{3}{*}{$\begin{array}{l}\text { Modelos } \\
\text { neoclásicos } \\
\text { del mercado } \\
\text { de trabajo }\end{array}$} & $\begin{array}{l}\text { Modelo de Estrategia de Búsqueda Óptima (Stigler, 1962). El egresado no tiene información } \\
\text { de ofertas laborales ni salarios e incurre en costos de búsqueda generalmente en el mercado } \\
\text { próximo. Selecciona una muestra salarial con un costo por cada salario examinado y elige } \\
\text { aleatoriamente las ofertas entre todas para estudiar las ofertas salariales y elegir aquélla más } \\
\text { elevada. }\end{array}$ \\
\hline & $\begin{array}{l}\text { Modelo de Búsqueda Salarial Secuencial (Mortensen, 1986). El egresado compara la oferta } \\
\text { salarial con el salario de reserva (el más bajo que lo convencería para aceptar trabajar) de tal } \\
\text { forma que maximice los beneficios esperados (Hall y Lieberman, 2005). Si la oferta salarial es } \\
\text { menor que el salario de reserva la rechaza (el salario estadísticamente se ubica en la zona de } \\
\text { rechazo). En caso contrario la acepta (fig. 1). }\end{array}$ \\
\hline & $\begin{array}{l}\text { Modelo del Número Óptimo de Contactos (Hamermesh y Rees, 1984). El que un egresado } \\
\text { obtenga su primer empleo depende del número de vacantes (por período) que sea capaz de } \\
\text { contactar según su nivel de esfuerzo. La búsqueda tiene unos costos crecientes, es decir, cada } \\
\text { vez que decide entrar en contacto con un empleador adicional es una acción cada vez más } \\
\text { costosa para el egresado desempleado. }\end{array}$ \\
\hline \multirow{3}{*}{$\begin{array}{l}\text { Modelos } \\
\text { de base } \\
\text { individual } \\
\text { o teorías } \\
\text { cognitivas }\end{array}$} & $\begin{array}{l}\text { Teoría Cognitivo-transaccional (Lazarus y Folkman, 1986). El egresado al afrontar dificultades } \\
\text { para insertarse al trabajo puede adoptar dos estrategias: paliativas o dirigidas al problema. } \\
\text { El adoptar una u otra dependerá de las expectativas generadas según la información que } \\
\text { percibe del contexto en relación con sus aspectos individuales (autoestima, experiencias } \\
\text { previas, soporte social e identidad vocacional). }\end{array}$ \\
\hline & $\begin{array}{l}\text { Teoría Cognitivo-conductual (Bandura, 1990). Las expectativas de autoeficacia que el egresado } \\
\text { tiene según su proceso de socialización y resocialización y que experimenta respecto a los } \\
\text { juicios de valor sobre sus propias capacidades y habilidades influirán en cómo organizará y } \\
\text { ejecutará sus actos. }\end{array}$ \\
\hline & $\begin{array}{l}\text { Teoría de la Disonancia (Festinger citado por Worchel et al. 2002). Existen las cogniciones } \\
\text { consonantes o congruentes y las cogniciones disonantes o incongruentes entre sí en el plano } \\
\text { psicológico (Bernardo, 2004). Así, ante la realidad laboral el egresado emprende determinadas } \\
\text { acciones (formación, búsqueda, información, cambio de expectativas y aspiraciones) } \\
\text { encaminadas a disminuir los aspectos disonantes. }\end{array}$ \\
\hline
\end{tabular}

Fuente: elaboración propia

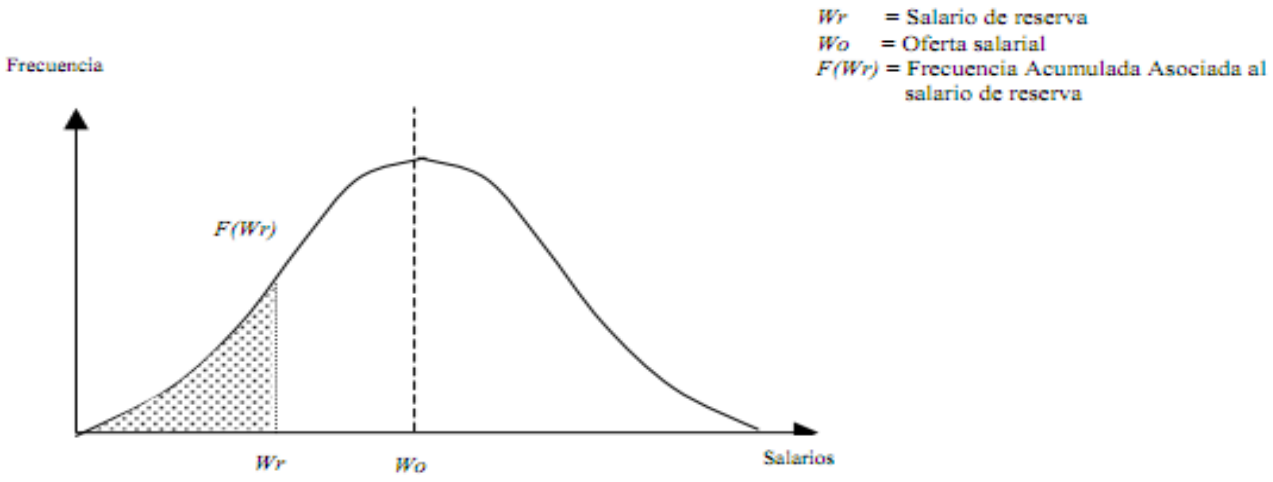

Figura 1. El salario de reserva según el Modelo de Búsqueda Salarial Secuencial Fuente: tomado de Uribe y Gómez (2006) 


\section{Metodología empleada}

El estudio fue exploratorio y descriptivo con un enfoque cualitativo empleando la fenomenología, pues ésta estudia un fenómeno tal y como es percibido, experimentado y vivido por una persona (Husserl, 1986), describe el significado de las experiencias vividas por los individuos (Creswell, 1998), aporta la intersubjetividad y la intuición en la comprensión de los fenómenos socioeducativos, y es útil para describir la realidad vivida por otras personas (Gurdián, 2007; Patton, 2002).

Se utilizó el estudio de caso pues se tuvo muy especial interés en un objeto de investigación buscando conocer el detalle de la interacción del caso con sus contextos (Stake, 2010), que fue el estudio de la particularidad y de la complejidad del proceso de inserción laboral de los graduados de la LCE.

Se estudiaron las dos primeras generaciones de egresados de la LCE, cuya composición se muestra en la tabla 2. Fueron dos las razones para estudiar a estas generaciones. En primer lugar se consideró que al ser los primeros egresados con una formación universitaria híbrida en la zona de influencia de la universidad en incursionar en el mercado laboral, estos egresados enfrentarían mayores retos y dificultades pues su perfil profesional no forma parte del imaginario del conjunto de empleadores. En segundo lugar, puesto que el tema de egresados universitarios híbridos es un área emergente de investigación educativa -al menos en México- el estudio aportaría evidencias empíricas y sentaría las bases para continuar cultivando esta línea de investigación en indagaciones futuras sobre la temática.

\section{Tabla 2. Población de egresados de la LCE estudiados en la investigación}

\begin{tabular}{|l|c|c|c|}
\hline Generación & Hombres & Mujeres & Total \\
\hline Primera (2005-2010) & 5 & 24 & $\mathbf{2 9}$ \\
\hline Segunda (2006-2011) & 4 & 18 & $\mathbf{2 2}$ \\
\hline Total & $\mathbf{9}$ & $\mathbf{4 2}$ & $\mathbf{5 1}$ \\
\hline
\end{tabular}

Fuente: Elaboración propia según datos de Servicios Escolares de la institución

No se utilizó una técnica estadística para la muestra pues la investigación cualitativa y el estudio de casos no pretenden la generalización. Los egresados fueron elegidos según características de interés para la investigación: los que se incorporaron prontamente al campo laboral y los que demoraron. Se empleó la técnica de muestreo bola de nieve, que permitió ir agregando a los informantes iniciales clave otros informantes y detener el muestreo según el principio de saturación. De esta manera se seleccionaron 10 egresados que compartieron información relevante para describir su inserción laboral como profesionistas universitarios híbridos.

Se entrevistó en profundidad a 10 egresados para conocer sus percepciones sobre las situaciones que favorecerían o dificultarían su tránsito de la universidad al campo laboral. La entrevista resultó ser el medio más eficaz pues es un método que implica "reiterados encuentros cara a cara entre el entrevistador y los informantes, encuentros éstos dirigidos hacia la comprensión de las perspectivas que tienen los informantes respecto de sus vidas, experiencias y situaciones, tal como las expresan en sus propias palabras" (Taylor y Bogdan 1994:101), y en la misma se privilegió la experiencia individual de los informantes en tanto sujetos y actores. Las entrevistas se desarrollaron de acuerdo con la guía correspondiente y desde la perspectiva de las identidades narrativas para dar cuenta de la trama argumental que da sentido a la multiplicidad de acontecimientos y experiencias de los entrevistados. 
La tabla 3 presenta las variables con sus dimensiones respecto del concepto central de inserción laboral que se incluyó en la guía de entrevista diseñada a partir de una serie de ejes problemáticos sobre el proceso de inserción laboral. Por razones de espacio en este trabajo sólo se presentan los resultados de la variable Búsqueda del primer empleo en las dimensiones Expectativas para su consecución y Autoconfianza y seguridad para la búsqueda. Todas las variables se analizan y describen en la tesis doctoral.

\section{Tabla 3. Definición operatoria del concepto central de inserción laboral}

\begin{tabular}{|c|c|c|}
\hline $\begin{array}{l}\text { C O N C E P T O } \\
\text { CENTRAL }\end{array}$ & VARIABLES & DIMENSIONES \\
\hline \multirow{5}{*}{$\begin{array}{l}\text { Inserción } \\
\text { laboral }\end{array}$} & Trabajo previo al egreso & $\begin{array}{l}\text { - } \quad \text { Trabajo durante los estudios } \\
\text { - } \quad \text { Características } \\
\text { coincidencia con los estudios que estaba } \\
\text { cursando }\end{array}$ \\
\hline & $\begin{array}{l}\text { Búsqueda del primer } \\
\text { empleo }\end{array}$ & $\begin{array}{ll}\text { - } & \text { Expectativas para su consecución } \\
\text { - } & \text { Autoconfianza y seguridad para la búsqueda. } \\
\text { - } & \text { Diligencia en la búsqueda } \\
\text { - } & \text { Ofertas recistas para su consecución } \\
\text { - } & \text { Caracteción } \\
\text { dificultaristicas person la búsqueda }\end{array}$ \\
\hline & $\begin{array}{l}\text { Características del primer } \\
\text { empleo }\end{array}$ & $\begin{array}{ll}\text { - } & \text { Tiempo para su consecución } \\
\text { - } & \text { Medios para su consecución } \\
\text { - } & \text { Coincidencia con los estudios cursados } \\
\text { - } & \text { Actividades desarrolladas } \\
\text { - } & \text { Satisfacción personal y profesional }\end{array}$ \\
\hline & Empleo actual & $\begin{array}{ll}\text { - } & \text { Medios para su consecución } \\
\text { - } & \text { Coincidencia con los estudios cursados } \\
\text { - } & \text { Actividades desarrolladas } \\
\text { - Nivel de satisfacción personal y profesional }\end{array}$ \\
\hline & Formación híbrida & $\begin{array}{ll}\text { - } & \text { La LCE y la consecución del empleo } \\
\text { - } & \text { La LCE versus la LC y la LA } \\
\text { - } & \text { Delimitación profesional de la LCE } \\
\text { - } & \text { Conocimiento del empleador de la LCE } \\
\text { - } & \text { Opinión del empleador y compañeros sobre los } \\
& \text { LCE }\end{array}$ \\
\hline
\end{tabular}

Fuente: elaboración propia

Para el estudio e interpretación de la información se realizó un análisis de contenido pues esta técnica es el "procedimiento para la categorización de datos verbales o de conducta, con fines de clasificación, resumen y tabulación" (Fox, 1981:709). La misma permitió identificar patrones discursivos, así como definir y caracterizar los factores que facilitarían u obstaculizarían la búsqueda del primer empleo de los egresados de la LCE.

\section{Resultados y discusión}

Los resultados se presentan en tres apartados. En el primero se abordan datos personales y del contexto familiar de los egresados. Seguidamente, se describen las representaciones sociales de los egresados acerca de los factores que favorecerían u obstaculizarían su inserción laboral. En el tercer apartado se discute sobre los resultados a partir de la teoría que sustenta la investigación. 


\section{Datos generales y de contexto de los egresados entrevistados}

Se entrevistó a diez egresados, seis mujeres (5 de la primera generación y 1 de la segunda) y cuatro hombres ( 1 de la primera generación y 3 de la segunda). Cinco de ellos tiene el título universitario (4 vía EGEL del CENEVAL ${ }^{2}$ y 1 vía defensa de tesis) y cinco no lo han obtenido (2 presentaron el EGEL pero no aprobaron, 2 nunca han intentado titularse y 1 no ha realizado servicio social, requisito para la titulación).

La edad promedio es de 24 años: el más joven de 23 años y el mayor de 27 años de edad. Todos son solteros y solteras. La mayoría (8) vive en la ciudad de San Juan Bautista Tuxtepec. Sólo dos viven y trabajan en otros lugares: una en la ciudad de Oaxaca y otra recientemente se trasladó a la ciudad de Guanajuato.

La escolaridad de los padres de los encuestados (6) es de sólo la educación básica (primaria hasta secundaria terminada), por lo que en la mayoría de los casos (9) constituyen la primera generación en su familia con acceso a la educación universitaria. Los padres generalmente se dedican a las actividades agrícolas, la producción de muebles de madera y escasamente son trabajadores asalariados mientras que las madres se dedican a las actividades del hogar y ayudan en la comercialización de los productos agrícolas y los muebles de madera.

Ocho de los diez entrevistados afirmaron que no querían estudiar la LCE pero que lo hicieron por las siguientes razones: sus padres "querían que se movieran en el mundo de los negocios y las empresas", sus padres no les permitieron salir a estudiar a otras ciudades, debido a la cercanía de la universidad a su hogar, por las becas que ofrece la institución o por los costos bajos de inscripción. Sólo dos de ellos eligieron libremente la carrera mencionando que no lo hicieron porque supieran de lo que trataba sino porque el "nombre de la carrera les parecía o sonaba padre y diferente a las demás" o porque habían escuchado que en esa nueva universidad casi no se perdían clases y todos los maestros tenían maestría o doctorado.

\section{Nivel de autoconfianza y opinión sobre la preparación profesional de los egresados previo a la búsqueda del primer empleo}

Durante el análisis de la información surgieron seis categorías: cuatro fueron consideradas como facilitadoras para la inserción laboral y dos como obstaculizadoras, tal como se muestra en la tabla 4.

Tabla 4. Categorías del nivel de autoconfianza y preparación profesional de los egresados

\begin{tabular}{|c|c|c|}
\hline \multicolumn{2}{|l|}{ Categorías } & \multicolumn{2}{|c|}{ Número de menciones } \\
\cline { 2 - 3 } & Facilitadoras & Obstaculizadoras \\
\hline 1. $\quad$ Formación multidisciplinaria & 8 & 1 \\
\hline 2. Preparación académica de la universidad & 7 & 0 \\
\hline 3. Prestigio de la universidad & 4 & 0 \\
\hline 4. Liderazgo y sociabilidad & 2 & 2 \\
\hline 5. $\quad$ Experiencia laboral & 1 & 3 \\
\hline 6. Promedio escolar & 1 & 1 \\
\hline
\end{tabular}

Fuente: elaboración propia 


\section{Categoría 1. Formación multidisciplinaria}

Esta categoría fue la más aludida y de naturaleza positiva para los egresados ya que consideraron que les transmitiría cierto nivel de seguridad y autoconfianza en la búsqueda del primer empleo. Consideraban, asimismo, que la formación universitaria híbrida representaba una ventaja para ellos pues afirmaron que en cuanto a "la preparación profesional era algo que yo consideraba que me ayudaría... Era como tener puntos a favor para conseguir empleo pues decía que si una persona sabe un poquito de contabilidad, de administración y otras aéreas administrativas tiene más posibilidades de entrar a una empresa (MA1GE1) $)^{3 \prime}$.

De acuerdo con las representaciones sociales de los egresados, de manera reiterativa consideraron que su formación universitaria era mejor que la de los egresados de carreras tradicionales o especializadas, situación que los motivaba para enfrentar con optimismo el proceso de inserción laboral. Un entrevistado mencionó que "en cuanto a la carrera yo decía que sí me habían enseñado un poco de todo, pues como que eso me daba más chances o posibilidades para encontrar un trabajo, como que la carrera nos da los elementos para encajar en varias partes de la empresa y también eso me animaba a veces (AM1GE5)". Asimismo, otro egresado indicó "sabía que la carrera de empresariales está muy completa y que por eso podemos ubicarnos en varias áreas de trabajo y saber eso a mí me animaba pues como que consideraba que llevaba un plus, algo más, en comparación con egresados de otras escuelas o universidades (JO2GE6)".

A través de los comentarios de los entrevistados se percibe una fuerte identificación con su formación multidisciplinaria que los distingue de otros profesionales del área económicoadministrativa, por lo que consideran que "en cuanto a la formación en la carrera, pues sí nos enseñaron muchas cosas aunque de manera general, como las bases para poder conseguir empleo en varias áreas en cualquier tipo de empresas (LE1GE9)", agregando que "en lo relacionado con la carrera de ciencias empresariales, es una carrera muy pero muy completa que no nos limita para desenvolvernos en cualquier área administrativa, contable y de mercadotecnia de las empresas (JE2GE10)".

A pesar del punto de vista optimista sobre su formación híbrida, es de interés destacar que en el proceso de búsqueda del primer empleo los egresados comenzaron a percibir ciertas problemáticas inherentes a la inserción en el campo laboral como el desconocimiento de la carrera (falta de reconocimiento social) por parte de los empleadores o de los responsables de reclutamiento y selección de personal de las empresas del entorno, entre otras. Es así que destacan que si bien "en cuanto a la preparación o la carrera de [ciencias] empresariales sí creo que de entrada resulta en una ventaja pues al saber de todo un poco eso significaba que podía colocarme en varios empleos. Sin embargo, en ninguna oferta de trabajo en las empresas o negocios de la ciudad solicitaban a alguien de [ciencias] empresariales y allí estaba o radicaba el problema creo yo (GI1GE7)".

\section{Categoría 2. Preparación académica de la universidad}

Los egresados refieren que la universidad les brindó una buena formación académica que los coloca en una mejor posición con respecto a los egresados de otras universidades de la región pues mencionan que "en las empresas o negocios al decir que uno va de la UNPA piensan que somos muy buenos en comparación con otros estudiantes o egresados como del Tecnológico, por ejemplo... Esa situación a mí me ayudó para sentirme segura en la búsqueda de trabajo (RO2GE2)". Asimismo mencionan que durante las entrevistas de trabajo entablaban comunicación con otros aspirantes provenientes de otras instituciones educativas afirmando que "nos poníamos a comparar las materias que llevamos y pues 
sí, creo que [los administradores] se quedan cortos con nosotros y eso me daba mucha seguridad al ir a buscar empleo (TA1GE3)". Algunos refieren que el modelo educativo de la universidad logró desarrollar en ellos habilidades y destrezas que contribuirían a una fácil adaptación a un puesto de trabajo ya que "ser egresado de la UNPA no es cualquier cosa, es sinónimo de estar acostumbrado a jornadas de mucho trabajo, a ser responsable, a saber trabajar en equipo, etc., pues eso caracteriza a nuestra formación en la universidad, a diferencia de otras escuelas donde sus alumnos se la llevan bien 'relax' y no les exigen tanto como a nosotros. Entonces, al tomar en cuenta la preparación que nos dan en la carrera de [ciencias] empresariales, esto me dio seguridad y confianza para ir a cualquier empresa a las entrevistas de trabajo (AN2GE8)".

De igual forma se destaca el hecho de que consideran la identificación con su formación universitaria como una ventaja que deben aprovechar para poder insertarse fácilmente en el mercado laboral pues afirman que "desde luego contribuyen a la autoconfianza la universidad y la carrera. La gente de las empresas no sabe mucho de la carrera pero de la UNPA tienen la idea de que es una universidad que exige mucho a los alumnos y que los prepara muy bien, entonces eso hay que aprovecharlo a nuestro favor (JE2GE10)".

\section{Categoría 3. Prestigio de la universidad}

Algunos de los egresados entrevistados consideran el prestigio de la institución donde se formaron como un aspecto favorable para poder insertarse de manera pronta en el campo laboral, pues con el paso del tiempo la forma de trabajo o el sistema educativo establecido han empezado a permear en el imaginario de la colectividad o del contexto externo inmediato a la universidad. Es así entonces que refieren lo que originó en ellos: "mucha confianza y seguridad me daba al ir a las entrevistas, cómo decirle... era algo así como un orgullo llegar y decir que era egresada de la UNPA (TA1GE3)". Otros consideran que su autoconfianza para la búsqueda del primer empleo es atribuida a la universidad, pues si bien es cierto que "la gente de las empresas no sabe mucho de la carrera pero de la UNPA tienen la idea de que es una universidad que exige mucho a los alumnos y que los prepara muy bien (JE2GE10)", de igual manera algunos entrevistados durante sus vacaciones experimentaron que su formación universitaria les estaba proporcionando los elementos para poder desempeñarse en el campo laboral y que recibían opiniones favorables tanto de su preparación como de la universidad. Así lo refiere Rosa: "en vacaciones un pariente que es contador me invitaba a ayudarle en el área de auditoría y yo al principio dije ¡nooo!, pues creí que quizá no podría, pero en fin, fui y para mi sorpresa sí pude con el trabajo. Por lo mismo yo dije: entonces sí me están preparando bien en la escuela, además en las empresas o negocios al decir que uno va de la UNPA piensan que somos muy buenos en comparación con otros estudiantes o egresados como del Tecnológico, por ejemplo, y eso me daba mucha confianza para ir a buscar empleo (RO2GE2)".

\section{Categoría 4: Liderazgo y sociabilidad}

Se encontró que la mitad de los entrevistados aseguraron que en la búsqueda del primer empleo se sintieron seguros debido a actitudes personales tales como el ser sociables o el poder comunicarse y relacionarse sin problemas con las personas, situaciones que desde su punto de vista contribuirían a la consecución pronta de un empleo. Así lo expresaron: "yo nunca me sentí con nervios o pena para ir a buscar empleo pues mi forma de ser muy amigable y sociable me ha sido de mucha ayuda. Esto me dio seguridad y confianza para ir a cualquier empresa a las entrevistas de trabajo (AN2GE8)". En algunos casos estas actitudes, unidas a una alta autoestima, contribuyeron para la obtención de un empleo aun antes de concluir la formación universitaria tal como lo narra un entrevistado: "mi autoconfianza o autoestima siempre ha sido muy alta, mi facilidad de palabra, el ser 
sociable y mostrar liderazgo para coordinar equipos de trabajo, todos esos factores sin duda ejercieron una influencia positiva para la búsqueda del primer empleo pues como quizá usted recordará faltaba un mes para que terminara la carrera y yo ya había ido a una entrevista a la cervecera y ya había logrado que me contrataran (JE2GE10)".

Por lo anterior, esta categoría representó un obstáculo para la inserción laboral de aquellos egresados que mostraron inseguridad, timidez y falta de sociabilidad, lo que poco contribuyó a la obtención del primer empleo. Así, algunos afirmaron que: "además, en ocasiones soy algo insegura y me ganan los nervios así que si juntamos todo eso pues creo que tenía muchas cosas que no me favorecían (AM1GE5)". En algunos casos esta situación fue un gran obstáculo a tal grado que originó que varios egresados no quisieran iniciar el proceso de búsqueda de empleo a pesar de sus necesidades económicas, tal como fuera el caso de Gina quien dice: "pues como ya le comenté la verdad yo tenía mucha pena para ir a buscar un empleo, creo que mi timidez y el no ser sociable eran mis grandes problemas y eso hizo que yo buscara muchos pretextos en casa para retrasar el tiempo de ir a buscar un trabajo (GI1GE7)".

\section{Categoría 5: Experiencia laboral}

En cuanto a esta categoría, en su mayoría la respuesta resultó negativa pues desde la opinión de los entrevistados la nula o escasa experiencia laboral al término de su formación universitaria representó un obstáculo para afrontar el proceso de búsqueda del primer empleo. Esto les generó inseguridad y nerviosismo en las entrevistas de reclutamiento y selección para un puesto de trabajo. Así lo refieren: "yo me sentía un poco insegura pues siempre lo primero que te dicen es que si se tiene experiencia laboral y aunque te pases cinco años en la uni[versidad] y vayas a hacer estancias profesionales pues eso de poco sirve para encontrar empleo (MA1GE1)". Otros egresados mencionaron lo mismo, reiterando que los períodos de prácticas profesionales en las empresas resultaron de muy poco valor para la adquisición de experiencia laboral: "Yo creo que en mi caso poca autoconfianza, pues siempre te piden experiencia en el trabajo y yo no tenía salvo el poquito trabajo que uno desarrolla en las estancias pero es muy poco y no creo que eso te sirva de algo (AM1GE5)". Leonel, un egresado procedente de un estrato socioeconómico bajo, añade a lo anterior el bajo nivel de conocimientos que adquirió mencionando que "yo la verdad me siento inseguro para ir a las entrevistas pero no porque tenga pena o sea tímido, más bien es porque creo que al no echarle ganas al estudio pues mis conocimientos no son muy buenos, además de que no tengo experiencia en el trabajo pues ni en los períodos de prácticas en las empresas me preocupé por estar en un área relacionada con la carrera (LE1GE9)". Cabe aclarar que en los tres casos anteriores en que los egresados afirmaron que las prácticas en las empresas no les ayudaron para su experiencia laboral, aquéllas fueron desarrolladas en empresas cuyos propietarios o responsables no eran parientes o conocidos. Dicha situación contrasta con lo mencionado por Rosa quién, durante el período de prácticas o trabajos desarrollados en vacaciones en empresas propiedad de familiares, logró obtener experiencia laboral favorable que contribuyó a tener una actitud positiva para la búsqueda del primer empleo. Tal como ella lo comentara: "pues la verdad yo pensaba que eso de ir a buscar empleo me iba a poner nerviosa pero a medida que pasaba el tiempo en la UNPA como que vas agarrando callo. Por ejemplo, en vacaciones un pariente que es contador me invitaba a ayudarle en al área de auditoría y yo al principio dije ¡nooo!, pues creí que quizá no podría, pero en fin fui y para mi sorpresa sí pude con el trabajo, por lo mismo yo dije: entonces si me están preparando bien en la escuela... y eso me dio mucha confianza para empezar a buscar trabajo (RO2GE2)". Sin lugar a dudas, abre una oportunidad para la investigación educativa en el sentido de indagar sobre las oportunidades para desarrollar 
habilidades para el trabajo o el nivel de aplicación de los conocimientos universitarios durante las prácticas profesionales en contextos diferenciados, es decir, en empresas sin o con vínculos familiares para los estudiantes practicantes.

\section{Categoría 6: Promedio escolar}

Esta categoría tuvo dos matices en sentidos muy diferenciados. Por una parte, algunos egresados refieren que un alto promedio escolar es un factor que les confería seguridad y confianza en la búsqueda del primer empleo y suponían que este elemento sería tomado en cuenta por los empleadores como símbolo de esfuerzo y dedicación y que hablaba mucho de sus actitudes y aptitudes como alumnos -las que podían trasladar al campo profesional. Así Lourdes refiere lo siguiente: “desde mi primera entrevista me sentía con mucha seguridad, creo que por dos razones principales: [en primer lugar] el llevar un buen promedio pues te brinda confianza. Yo sé que lo que las empresas quieren es que el candidato tenga experiencia pero bueno, digo, si uno es nuevo y no tiene experiencia, lo menos que yo como entrevistador esperaría es traer buenas notas pues eso significa esfuerzo y dedicación en los estudios y, en segundo lugar, el hecho de que los profesores nos hicieran participar en prácticas de consultoría empresarial con empresas reales en donde teníamos que pararnos frente a los empresarios para decirles las debilidades y fortalezas encontradas en sus negocios y justificar nuestras recomendaciones. Eso te ayuda a fortalecer tu autoestima y a generar confianza en ti mismo" (LO1GE4).

Tomando en cuenta que en el imaginario de los egresados el tener un buen promedio escolar es una buena carta de presentación ante los empleadores, aquellos que tuvieron un bajo rendimiento académico se ven limitados o disminuidos en su autoconfianza para la búsqueda del primer empleo. Tal fue el caso de Leonel quien, al momento de la entrevista, no trabajaba. Él comentó: "yo la verdad me siento inseguro para ir a las entrevistas pero no porque tenga pena o sea tímido, más bien es porque tuve el promedio más bajo de mi generación y pues creo que al no echarle ganas al estudio mis conocimientos no son muy buenos... (LE1GE9)".

\section{Discusión de los resultados a la luz de los modelos de inserción laboral}

Las expectativas del proceso de búsqueda del primer empleo son bien explicadas mediante el enfoque psicosocial (variables sociales e individuales) pues las representaciones sociales que los egresados tenían del mercado laboral dependieron en muchos casos de situaciones externas y en otros de sus circunstancias personales que, en ocasiones, fueron decepcionantes por la falta de competencias académicas para desempeñar un puesto de trabajo, la inexperiencia laboral y el desconocimiento del mercado de trabajo. Por lo anterior, los niveles de autoconfianza y opinión sobre la preparación profesional de los egresados previo a la búsqueda del primer empleo pueden ser interpretados mediante los modelos teóricos de base individual que consideran al egresado como responsable principal de su inserción laboral.

Al intentar obtener su primer empleo, los egresados adoptaron "estrategias dirigidas a resolver el problema" (Lazarus y Folkman, 1986), y sus expectativas se vieron condicionadas de manera tanto favorable como desfavorable debido a las informaciones que percibieron del contexto en relación a aspectos individuales tales como la autoestima, la identidad vocacional, las experiencias previas y el soporte social. En cuanto a la autoestima consideraron que el ser sociables, el saber comunicarse con los demás, el trabajar en equipo y el mostrar liderazgo en sus actividades académicas sin dudas contribuirían de manera favorable para poder afrontar sin nerviosismo la búsqueda del primer empleo. 
En cuanto a la identidad vocacional consideraron que su formación universitaria híbrida o multidisciplinaria les brindaría la oportunidad de poder moverse en muchas áreas de una empresa teniendo más oportunidades de colocarse prontamente en el mercado laboral en comparación con otros egresados que recibieron una formación tradicional y especializada.

En cuanto al soporte social (prestigio de la universidad) reconocían que si bien los empleadores de la zona de influencia de la universidad no conocían mucho de la LCE, sí sabían del modelo académico estricto y exigente de la universidad siendo esto desde su imaginario un elemento positivo para su inserción laboral ya que les trasmitió mucha confianza y seguridad en las entrevistas. Para ellos "era algo así como un orgullo llegar y decir que era[n] de la UNPA".

Los juicios de valor de los entrevistados acerca de sus capacidades para llevar a cabo con éxito determinadas tareas en el campo laboral, sus experiencias de éxitos y fracasos así como otros mecanismos de apoyo influyeron ya sea positiva o negativamente en sus expectativas para la consecución del primer empleo, tal como lo mencionan los supuestos de la "Teoría Cognitivo-conductual" (Bandura, 1990), que afirman que las expectativas de autoeficacia de las personas se fundamentan en los juicios de valor que cada individuo tiene sobre sus capacidades y habilidades. De esta manera, los egresados suponían que su formación híbrida les otorgaba ventaja en comparación con otros profesionales del área económico-administrativa pues afirmaron estar más preparados para poder insertarse y desempeñarse en muchas áreas de una empresa.

En cuanto a sus experiencias de éxitos y fracasos consideraron que el haber concluido una carrera universitaria en un modelo educativo tan exigente (cinco años de carrera, horario de 8:00 h a 19:00 h, programa de lectura y de idioma extranjero a lo largo de toda su formación, entre otros) les brindaba una buena carta de presentación así como confianza y seguridad suficientes para ir en busca del primer empleo. No obstante, la mayoría de los entrevistados consideró que la falta de experiencia laboral representaría un obstáculo para la búsqueda del empleo pues los períodos de prácticas profesionales en poco contribuyeron a desarrollar experiencia laboral, situación que afrontaron con diversos mecanismos de apoyo tales como el prestigio de la universidad en la zona de influencia, su formación universitaria híbrida y las habilidades desarrolladas durante su formación como el trabajo en equipo, el liderazgo, la comunicación verbal y escrita, entre otros.

Los resultados obtenidos también son explicados por la Teoría de la Disonancia (Festinger, citado por Worchel et al., 2002), quien afirma que debe existir una congruencia entre lo que un individuo sabe o cree y lo que hace, por lo cual éste se sentirá motivado a lograr y mantener la congruencia en sus cogniciones (cualquier conocimiento, opinión o creencia sobre el medio, sobre uno mismo o sobre la conducta de uno mismo). De tal forma, se encontraron cogniciones consonantes ante el proceso de búsqueda del primer empleo. Algunos egresados afirmaron no estar nerviosos y sentirse seguros en las entrevistas pues a partir de sus cogniciones suponían que podrían insertarse con éxito en el mercado laboral como correspondencia a sus esfuerzos y logros académicos, todo ello representado en una credencial universitaria con alto promedio. En sentido inverso, los egresados con bajo rendimiento académico fueron aquellos que sintieron mucha inseguridad, temor, baja autoestima y en ocasiones hasta inventaron diversas excusas para retrasar el proceso de búsqueda del primer empleo. 


\section{Conclusiones}

En este acercamiento exploratorio de los factores que desde la opinión de los entrevistados facilitarían u obstaculizarían su inserción laboral se encontraron tres aspectos que contribuyeron a que tuvieran una actitud positiva para ir en busca del primer empleo:

1) La formación universitaria híbrida que representaba un plus o un extra que los colocaba en una mejor situación en comparación con egresados de otras universidades,

2) La calidad de su formación académica por un modelo educativo exigente (horario de tiempo completo, programas de lectura y de idioma extranjero, profesores con maestría y doctorado), que desde su óptica logró desarrollar en ellos habilidades y actitudes para solucionar problemas, trabajar en equipo, ejercer liderazgo y ser sociables y,

3) El prestigio de la universidad por el nivel de exigencia de su modelo educativo que a la fecha ya había permeado en el imaginario colectivo de los empleadores de la zona de influencia.

En menor medida se identificaron elementos que poco contribuyeron para que los egresados procedentes de estratos socioeconómicos bajos afrontaran con denuedo la búsqueda del primer empleo pues generalmente refieren que temían ir a una entrevista de trabajo por timidez y nerviosismo y por falta de experiencia laboral, todo ello sumado a un bajo rendimiento académico.

Los entrevistados refieren que sus expectativas ante la búsqueda del primer empleo se vieron disminuidas. Si bien es cierto que consideraban que contaban con una mejor preparación que los egresados de carreras tradicionales por su formación multidisciplinaria y/o híbrida, y que su universidad de procedencia era reconocida por su modelo educativo muy exigente, en el proceso de búsqueda del primer empleo se encontraron con el obstáculo de la falta de reconocimiento social de su profesión. Mencionaron que las empresas o empleadores "no saben nada de la carrera" y que nunca encontraron ofertas de trabajo donde solicitaran a Licenciados en Ciencias Empresariales, por lo que debieron acudir a entrevistas de trabajo dirigidas a Licenciados en Administración o Licenciados en Contaduría. Estos resultados corroboran lo que se dice de las profesiones híbridas en el sentido de que carecen de reconocimiento social, lo que origina la falta de oferta de puestos de trabajo para los egresados pues los empleadores desconocen las áreas de la empresa donde pueden ser ubicados, situación que pone en tela de juicio las ventajas de las carreras hibridas.

A manera de cierre hay que señalar que, a medida que la investigación se fue desarrollando, se comprobó que aquellas percepciones de los egresados acerca de los factores que facilitarían la inserción laboral antes de asistir a una entrevista para conseguir el primer empleo, en el plano de los hechos se vieron contradichas pues en algunos casos dichos factores no correspondían a las representaciones sociales de los egresados y se convirtieron en obstaculizadores para su pronta incorporación al trabajo.

\section{Referencias bibliográficas}

Bandura, A. (1990). Selective activation and disengagement of moral control. En Journal of Social Issue 46(1), 27-46. Stanford.

Barrón, C. (coord.) (2003). Los estudios de seguimiento de egresados en el periodo 1992-2002. En Reynaga Obregón, S. (coord.). Educación, trabajo, ciencia y tecnología. La investigación educativa en México 1992-200, 6, 30-103. México: COMIE 
Barrón, C. y Gómez, J. (2004). Las nuevas profesiones en las instituciones de educación superior. En Ángeles Valle (coord.). Las profesiones en México frente al mercado de trabajo. (pp. 47-94). México: CESU-UNAM.

Bernardo, J. (2004). Una didáctica para hoy: cómo enseñar mejor. Madrid: Ediciones RIALP.

Celis, J. y Gómez, V. (2005). Factores de innovación curricular y académica en la educación superior. En Revista Electrónica de la Red de Investigación Educativa, 1(2), 1-16.

Creswell, J. (1998). Qualitative and inquiry research design. Choosing Among Five Approaches. Universidad de Nebraska. Lincoln: Sage Publications.

CUP. (2009). Modelo Educativo del Subsistema de Universidades Politécnicas. Recuperado de http://www.upvictoria.edu.mx/upv/docs/nuestra_universidad/modelo_educativo_ unipols.pdf

Damián, J. (2014). La formación universitaria híbrida: Retos y oportunidades. En Revista Electrónica Actualidades Investigativas en Educación, 14(2), 01-22.

De Ibarrola, M. (2007). Formación escolar para el trabajo: posibilidades y límites. Experiencias y enseñanzas del caso mexicano. En De Ibarrola (edit.), Nuevas tendencias de la formación escolar para el trabajo. OIT/Cinterfor.

De Miguel, M. (1998). Los estudios universitarios y la inserción en el mundo profesional. Seguimiento de una cohorte (COU, curso 1986/87). Oviedo: Universidad de Oviedo.

DGEST. (2009). Diseño e innovación curricular para el desarrollo de competencias profesionales en el SNEST. Recuperado de http://www.dgest.gob.mx

Fox, D. (1981). El proceso de investigación en educación. Pamploma: Eunsa.

García-Blanco, J. y Gutiérrez, R. (1996). Inserción laboral y desigualdad en el mercado de trabajo: cuestiones teóricas. En Revista Española de Investigaciones Sociológicas, 75 (96), 269-293.

Gurdián, A. (2007). El Paradigma Cualitativo en la Investigación Socio-Educativa. Coordinación Educativa y Cultural Centroamericana (CECC) - Agencia Española de Cooperación Internacional (AECI). San José.

Hall, R. y Lieberman M. (2005). Microeconomía: Principios y aplicaciones. México: Thomson Editores.

Hamermersh, D. y Rees, A. (1984). Economía del trabajo y los salarios. Madrid: Alianza Universidad.

Holguín, C. (2011). Carreras híbridas, cambiando el paradigma de la especialización. En Revista UNIVERCITIES, 1(4), 3-4.

Husserl, E. (1986). Ideas relativas a una fenomenología pura y una filosofía fenomenológica. México: Fondo de Cultura Económica. 
leepo. (2005). El Sistema de Universidades Estatales de Oaxaca. Universidades para el desarrollo. México: Instituto Estatal de Educación Pública de Oaxaca.

Jiménez, M. (2009). Trayectorias laborales y movilidad de los biólogos agropecuarios de la Universidad Autónoma de Tlaxcala. En Perfiles educativos, 31(126), 56-79.

Lazarus, R. y Folkman, S. (1986). Estrés y procesos cognitivos. México: Martínez Roca

Mortensen, T. (1986). Búsqueda de empleo y análisis del mercado laboral. En Ashenfelter y Layard (comps.): Manual de economía del trabajo, Tomo II, Ministerio de Trabajo y Seguridad Social. Madrid. 1111-1198.

Páez-Gutiérrez, M. (2011). La intervención educativa como profesión emergente. (Tesis doctoral, Doctorado Interinstitucional en Educación. Guadalajara, México: ITESO) Recuperado de http://rei.iteso.mx/bitstream/handle/11117/1177/Tesis_II_Maricela_Paez. pdf?sequence $=2$

Patton, Q. (2002). Qualitative research \& evaluation methods. Londres: Thousand Oaks, Sage Publications.

Sáez, F. (2007). Necesitamos ingenieros sociotécnicos. Conferencia presentada en el Seminario La ingeniería ante las Ciencias Sociales y las Humanidades.

Stake, R. (2010). Investigación con estudio de casos. Madrid: Morata.

Stigler, G. (1962). Information in the Labour Market. En Journal of Political Economy, Vol. 70, 94-105. Chicago.

STPS. (2015) ¿Cómo será el trabajo en el futuro? Secretaría de Trabajo y Previsión Social. Recuperado de: http://www.empleo.gob.mx/es_mx/empleo/como_se_espera_que_sea_ el_trabajo_en_el_futur

Taylor, S. y Bogdan, R. (1994). Introducción a los métodos cualitativos de investigación. La búsqueda de significados. Barcelona: Editorial Paidós.

Universia. (2010). El futuro está en las carreras híbridas. Recuperado de http://noticias. universia.net.mx/en-portada/noticia/2010/03/30/193271/futuro-esta-carreras-hibridas. html

Uribe, J. y Gómez, L. (2006). Canales de búsqueda en el mercado laboral colombiano 2003. En Uribe García José Ignacio (comp.). Ensayos de economía aplicada al mercado laboral. 351-384. Cali: Universidad del Valle.

Vernières, M. (1997). "La notion d'insertion professionnelle". En Vernières (ed), L'insertion professionnelle. Analyse et débats. 9-22. Paris: Economica.

Worchel, S., Cooper, J., Goethals, G. y Olson, J. (2002). Psicología social. México: Thomson editores.

\section{(Endnotes)}


1 Se presentan avances de la investigación "Factores que facilitan y obstaculizan la inserción laboral de los egresados de carreras híbridas. El caso del Licenciado en Ciencias Empresariales de la Universidad del Papaloapan", para la obtención del Doctorado en Enseñanza Superior.

2 En México es el Examen General de Egreso de Licenciatura (EGEL) aplicado a nivel nacional por el Centro Nacional de Evaluación (CENEVAL), que es válido para la obtención del título de licenciatura.

${ }^{3}$ Se asignaron claves a los informantes para su anonimato, así MA1GE1 significa, MA: nombre, 1G: generación y E1: número de entrevistado. En este caso nos referimos a María, egresada de la primera generación y primera entrevistada. 